\title{
Assessment of roundworm species prevalence in cattle, sheep and goats slaughtered at Lafia Abattoir, Nasarawa State, Nigeria
}

\author{
Adua M. M., Idahor K. O.* and Christopher S. K. \\ Department of Animal Science, Nasarawa State University, Keffi, Shabu-Lafia Campus, P.M.B. 135, Lafia, 950101, \\ Nigeria. \\ *Corresponding author. Email: mangonlen@yahoo.com
}

Copyright (@ 2017 Adua et al. This article remains permanently open access under the terms of the Creative Commons Attribution License 4.0, which permits unrestricted use, distribution, and reproduction in any medium, provided the original work is properly cited.

Received 29th October, 2017; Accepted 20th November, 2017

\begin{abstract}
Intestinal parasites pose a great constraint to livestock production and cause high incidence of mortality and low production in livestock. This study was designed to identify the roundworm species infections in cattle, sheep and goats that were slaughtered at Lafia abattoir during the rainy season (April to June, 2016). The aim was to sensitize livestock stakeholders to strategize effective means of disrupting the life cycles of the roundworms in order to prevent their widespread within the herds. Faecal samples were collected from 22 cattle, 25 sheep and 23 goats and were examined by simple floatation method and microscopy for the presence of roundworms. Results showed that out of a total of 70 animals examined, 36 representing $51.4 \%$ of the animals were infected with various species of roundworms. Those found in the animals examined included Haemonchus contortus, Bunostomum phlebotomum, Ascaris suum and Neoascaris vitulorum. It was observed that both sexes of all the animal breeds examined were infected, though males were more susceptible than the females. Animals in all the age categories were infected and those on extensive management system were more infected than those in semi-intensive. Since different species of roundworms were found in cattle, sheep and goats slaughtered at Lafia abattoir, it indicated that there was probably high prevalent rate of roundworms in the area. More so, mixed species infection of Ascaris suum and Neoascaris vitulorum were recorded in goats, suggesting severe burden that may hinder optimum physiological performance. It could be necessary therefore to advise that careful disposal of the gastrointestinal contents, regular deworming, implementation of strict biosecurity measures and intensive animal production system should be adopted in the study area. This may disrupt the life cycles of the roundworm species thus, preventing parasitic infections from spreading to other animals in the study area.
\end{abstract}

Key words: Abattoir, ascaris, gastrointestinal parasites, ruminant animals.

\section{INTRODUCTION}

Livestock like cattle, sheep and goats are naturally multipurpose animals reared for household income, production of meat, milk, wool, manure, hides and skin (Mulugete et al., 2011). But in Nigeria, cattle are mainly kept for meat, milk and hides production while, sheep and goats are maintained as subsistence animals for meat and skin. Essentially, there is high demand for these ruminants not only for food but also for religious and social ceremonies and as a source of income. Livestock are affected by different kinds of gastrointestinal parasites which may be classified into three groups: roundworms or nematodes, flukes or trematodes, tapeworms or cestodes (Love and Hutchinson (2003). According to Loukopoulos et al. (2007) a parasite is an undesirable organism that exists in or on the body of another living organism or host.

RIM (1992) stated that roundworms are by far the most economically important internal parasites of sheep, goats 
and cattle and those found in the gastrointestinal tract are more in number and economically important than those found in other organs. Williamson and Payne (1978) reported that the nematodes that were commonly parasitic to livestock included strongyles and ascarids. Meanwhile, Haemonchus contortus was reported to be one of the most abundant infectious agents in ruminants (especially sheep) and it dwells in abomasum where it causes great economic damage (Love and Hutchinson 2003). Ascaris is a genus of parasitic nematodes (helminths) known as the "small intestinal roundworms". Typically, Ascaris suum and Ascaridia spp (especially, Neoscaris vitulorum, Parascaris equorum) infect pigs, calves, horses and poultry (Williamson and Payne, 1978). Nematodes of the digestive tract produce their harmful effects in a variety of ways. For instance, those that migrate extensively such as Ascaris suum and Parascaris equorum were reported to cause traumatic and inflammatory damage in the liver and lungs (Das, 2005; Love and Hutchinson, 2003). Williamson and Payne (1978) stated that hookworms especially Haemonchus cortortos and other blood-sucking species cause anaemia resulting in death of the host.

Roundworms are economic important parasites that are highly infectious and transmissible among livestock. It becomes imperative therefore, to carry out regular surveillance in order to map out possible ways of breaking the life cycles of these parasites to prevent possible widespread and loss of livestock.

\section{MATERIALS AND METHODS}

\section{Description of the study area and climatic condition}

The study was conducted in the months of April, May and June, 2016 at Lafia Central Abattoir in Lafia Local Government Area, Nasarawa State with about 330,712 inhabitants (NPC, 2006). Lafia is located within the north central zone of Nigeria. Lafia is situated on latitude $08^{\circ}$ $35^{\prime} \mathrm{N}$, longitude $08^{\circ} 34^{\prime} \mathrm{E}$ with an altitude of $181 \mathrm{~m}$ above sea level, temperature ranging from 32 to $35^{\circ} \mathrm{C}$, relative humidity between 58 and $63 \%$, average day light of 9 to 12 hours and average rainfall of $1,400 \mathrm{~mm}$ per annum (NIMET, 2011). The vegetation consists of different species of trees, shrubs, leguminous browse plants and grasses with undulated terrain. Farmers in the area rear cattle, poultry, goat, sheep and pig among other livestock. It has a tropical climate with two distinct seasons (wet and dry seasons), with the wet season spanning from April to September and dry season covering October to March. The involvement of Lafia people in slaughtering of animals, processing, marketing and consumption of meat in various forms may vary slightly depending on the tribe, culture and religious belief. However, it could be obvious that both young and old people are actively involved in various forms of livestock chain activities especially in the rural settlements (NPC, 2006).

\section{Sampling technique}

Most of the animals were slaughtered immediately after bringing them from Lafia Livestock Market, Shinge and the environs by merchants instead of keeping them in the liarrage for some time and it was not clear whether they were certified by the abattoir operators or not. Faecal samples were collected from the duodenum and large intestines of the first 5 animals each of the breeds slaughtered at the abattoir on weekly bases for 90 days (April to June, 2016). The faecal samples collected from each of the animals were pooled in universal bottles, mixed and labelled properly and aliquots were taken to the Parasitology Laboratory, National Veterinary Research Institute Vom, Plateau State, Nigeria for the determination of roundworm species. Sample from each animal was processed and analysed the same day and those that were not analysed the same day were discarded and fresh samples were collected where necessary. Information on the age and management system of the animals was provided by the merchants and the sex was determined visually before slaughtering. The age was confirmed by the dentition pattern as described by Merck (2015).

\section{Parasitological examination}

Following the protocols of Chessbrough (2005), $2 \mathrm{~g}$ of the faecal samples was weighed using sensitive weighing scale, zinc sulphate added to make about two-third of its volume and the mixture was centrifuged at 1,200 rpm for 5 minutes. The mixture was homogenized using a glass stirrer, sieved to trap coarse debris on the gauze and then decanted. Floatation medium was later added to the filtrate filling it up to the brim until a convex meniscus was formed on the test tube. A cover slip was placed on the test tube to cover the filtrate and left for about three minutes. Thereafter, the cover slip was carefully removed, placed on clean slide and viewed under the microscope (Olympus Microscope ${ }^{\circledR}$ Tokyo, Japan) at 10x and $40 x$ magnifications.

\section{Data collection and analysis}

Roundworm species occurrence in the samples was recorded based on sex, age and management system of the animal species investigated. The values were subjected to simple descriptive statistics as described by Adesoye (2006). 
Table 1. Roundworm species found in cattle, sheep and goats slaughtered at Lafia abattoir.

\begin{tabular}{lcccccc}
\hline \multirow{2}{*}{ Roundworm species } & \multicolumn{3}{c}{ Cattle $(\mathbf{n}=\mathbf{2 2})$} & Sheep $(\mathbf{n}=\mathbf{2 5})$ & \multicolumn{3}{c}{ Goats $(\mathbf{n}=\mathbf{2 3})$} \\
\cline { 2 - 7 } & Freq. & $\%$ & Freq. & $\%$ & Freq. & $\%$ \\
\hline Haemonchus contortus & 5 & 7.1 & 10 & 14.3 & 10 & 13.3 \\
Bunostomum phlebotomum & 2 & 2.9 & 0 & 0.0 & 3 & 4.3 \\
Ascaris suum & 3 & 4.3 & 2 & 2.9 & 0 & 0.0 \\
Mixed infection of Ascaris suum and Neoascaris vitulorum & 0 & 0.0 & 0 & 0.0 & 1 & 1.4 \\
Total & 10 & 14.3 & 12 & 17.1 & 14 & 20.0 \\
\hline
\end{tabular}

Freq.: Frequency; n: Animal population size.

Table 2. Sex, age and management system of roundworm-infected cattle, sheep and goats slaughtered at Lafia abattoir.

\begin{tabular}{lcc}
\hline Parameters & Frequency & Percentage \\
\hline Sex & & \\
Male & 22 & 31.4 \\
Female & 14 & 20.0 \\
Total & 36 & 51.4 \\
& & \\
Age & & \\
$1-2$ years & 3 & 4.3 \\
$3-5$ years & 20 & 28.6 \\
$>5$ years & 13 & 18.5 \\
Total & 36 & 51.4 \\
& & \\
Management system & & \\
Extensive & 32 & 45.7 \\
Semi-intensive & 4 & 5.7 \\
Total & 36 & 51.4 \\
\hline
\end{tabular}

\section{RESULTS}

Table 1 shows the prevalence of roundworm-infected cattle, sheep and goats slaughtered at Lafia abattoir. A total of 36 representing $51.4 \%$ of the 70 animals screened were infected. The species of the roundworms found were Haemonchus contortus, Bunostomum phlebotomum, Ascaris suum and Neoascaris vitulorum. A case of mixed (Ascaris suum and Neoascaris vitulorum) species infection (1.4\%) was observed only in goats.

Presented in Table 2 are the sex, age and management system distribution of roundworm-infected cattle, sheep and goats slaughtered at Lafia abattoir. It was observed that more males $(31.4 \%)$ were infected than females (20.0\%), 3 to 5 years old animals were most infected $(28.6 \%)$ followed by animals that were more than 5 years old $(18.5 \%)$ with the least prevalent rate $(4.3 \%)$ recorded among 1 to 2 years old animals. Out of the 36 animals infected, 32 representing $45.7 \%$ were reared under extensive system.

\section{DISCUSSION}

It was observed that cattle, sheep and goats slaughtered at Lafia abattoir during the study were infected with roundworms. This observation corroborated the findings of Okaiyeto et al. (2008) that gastrointestinal parasites were prevalent in sheep and goats reared in northern region of Nigeria. The roundworm prevalent rate in the present study was however lower than 77 to $100 \%$ reported by Fakae and Fakae (2009) in some parts of Nigeria but was higher than 18.9 to $42.1 \%$ reported in ruminants in Niger State (Agbajelola et al., 2015). The prevailing climatic conditions especially rainfall and temperature may have favoured the development, survival and proliferation of the parasitic nematodes (Brito et al., 2005; Latha et al., 2004; Chiejina and Emehelu, 1984). This perhaps explained the prevalent rate observed in the study which was conducted during the rainy season in the region. According to Gillian et al. (2004), gastrointestinal parasites were becoming a difficult and major problem for animal production with attendant influence on cost of production. This emphasised the earlier report by Mulugeta et al. (1989) that roundworms were enormous in farm animals causing major production losses. It was stated that high cost of drugs, possible residual effects on both the animals and humans as well as the adverse effects of these parasites seemed to be pushing small scale farmers out of the industry.

Therefore, breaking the life cycle of the roundworms by carefully disposing or incinerating the gastrointestinal contents at the designated areas at the abattoirs becomes necessary. The farmers could also be supplied with anthelmintic regularly at no cost to treat the animals in order to control spread of infections within the herds. More importantly, extension officers should be attached to the abattoirs to administer appropriate drugs to the animals kept in the liarage in order to control diseases transmission especially zoonosis. But the drug withdrawal period should be strictly adhered to, in order to ensure wholesome and safe carcasses for human consumption.

Apparently, sex did not influence the rate of roundworm infection in the animals examined but the males were 
more susceptible than the females. This observation corroborated with the findings of Yeasmin et al. (2014) that rams were more susceptible to parasites but contradicted the findings of Lloyd (1983) who reported that female animals were more susceptible to any infection. The observed disparity may be largely due to the management systems adopted in the studies. Meanwhile, age and management system seemingly determined the infection rate as only the adults and animals in extensive management system were highly infected and these observations further explained the higher degree of susceptibility of adult ruminants. These findings were similar to the reports by Yeasmin et al. (2014) and Church (1993), which might be due to their feeding habit. However, it opposed the findings of Chakrabarty (1994) and Shahadat et al. (2003) who recorded higher prevalence of parasites in young ruminants. It is expected that the adults may build resistance to some of the prevailing diseases and the survival of animals on free range may be dependent on the prevailing environmental factors. As a result, intensive animal production system where the recommended sex ratio and other routine management practices are adhered and to may be preferred in the study area to minimize recycling of roundworm infections.

\section{Conclusion}

Although, different species of roundworms were found in cattle, sheep and goats slaughtered at Lafia abattoir, it was observed that Haemonchus contortus infected all the animal breeds examined and it was apparently the roundworm with the highest burden in cattle, sheep and goats examined. More so, mixed roundworm species infection was recorded in goats suggesting severe burden that may emanate from composite effects, capable of hindering optimum physiological performance in the area. It was revealed that both sexes were infected with roundworms thus, sex may not play significant role in parasites control strategy.

It was shown that the adult animals were more susceptible to the prevailing parasites, compared to the younger animals and semi-intensive system apparently reduced the parasitism rate among the animals studied. Consequently, stringent measures such as careful disposal or incineration of the gastrointestinal contents, regular use of anthelmintic and engagement of qualified and committed extension officers, may be needed to control roundworm infections in the study area. More significantly, intensive animal production system where strict biosecurity measures are implemented may be preferred in the study area. These measures may result in disrupting the life cycles of the roundworms, thereby averting reoccurrence among the herds.

\section{CONFLICT OF INTEREST}

The authors declare that they have no conflict of interest.

\section{REFERENCES}

Adesoye, P. O. (2006). Practical Guide to Statistical Analysis for Scientists (A Primer Edn.). Debo Prints, Ibadan, Nigeria, p.189.

Agbajelola, V. I., Falohun, O. O., Jolayemi E. B., \& Obebe, O. O. (2015). Prevalence of intestinal helminths and protozoa parasites of ruminants in Minna, North Central, Nigeria. J. Agric. Vet. Sci. 8 (11), 27-32.

Brito, D. R. B., Santos, A. C. G., \& Guerra, R. M. S. N. C. (2005). Ectoparasites in goat and sheep herds from the Alto Mearim and Grajau micro region, State of Maranhao. Revista Brasileria de Parasitologia Veterinaria, 14, 59-63.

Chakrabarty, D. (1994). Blood biochemical profiles in Fasciola, Haemonchus and Dictyoculus species infection in goats- a comparative study. Ind. Vet. J., 71, 286-288.

Chessbrough, M. (2005). Medical Laboratory Manual for Tropical Countries. 2nd edition, University press Cambridge, pp 200-357.

Chiejina, S. N., \& Emehelu, C. O. (1984). Seasonal changes in pasture populations of infective larva of gastrointestinal nematodes of cattle in Eastern Nigeria. Res. Vet. Sci., 37, 144-147.

Church, D. C. (1993). The Ruminant Animal Digestive Physiology and Nutrition. Waveland Press Inc. Illinois.

Das, S. K. (2005). Handbook of Veterinary Practitioners. Printed by Diamond Agencies Pvt Ltd, B-125 Sec 63, Noida and published by Mrs Usha Raj Kumar, for Kalyani publishers, New Delhi-110002.

Fakae, B. B., \& Fakae, S. N. (2009). Further studies on the development and availability of infective larvae of Bovine gastrointestinal trichostrongyloides on pasture in eastern Nigeria, Veterinary Parasite, 28, 143-152.

Gillian, S., Behnke, J. M., Buttle, D. J., \& Duce, L. R. (2004). Natural plant cysteine proteinases as anthelminths. Trends in Parasitology. 20, 322-327.

Latha, B. R., Aiyasami, S. S., Pattabiraman, G., Sivaraman, T. and Rajavelu G. (2004). Seasonal activity of ticks on small ruminants in Tamil Nadu State, India. Tropical Animal Health and Production. 36, 123-133.

Lloyd, S., (1983). Effect of Pregnancy and lactation up on infection. Vet. Immunol., Immunopathol., 4, 153-176.

Loukopoulos, P., Komnenou, A., Papadopoulos, E., Psychas, V. (2007). Lethal Ozolaimus megatyphlon infection in a green iguana (Iguana iguana rhinolopa). J. Zoo and Wildlife Med., 38(1), 131-134.

Love, S. C. J., \& Hutchinson, G. W. (2003). Pathology and diagnosis on internal parasites in ruminants. Gross Pathology of Ruminants. Proc. 350, Post Graduate Foundation in Veterinary Science, University of Sydney, Sydney.Pp. 309338.

Merck. (2015). The Merck Veterinary Manual. Estimation of age by examination of the teeth, dental development. Merck manuals 2009-2015, Merck Sharp \& Dohme Corp., a subsidiary of Merck \& Co., Inc., Kenilworth, N.J., U.S.A.

Mulugeta, H. S., Tafesse, M., Getachew, W., Kinfe, G., Getchew, T., \& Teshome, Y. (1989). The significant of 
helminth parasites in livestock improvement production. Institute of Agricultural Research (IAR) proceedings of the $3^{\text {rd }}$ National livestock Conference, 24-26 May 1989, Addis Ababa, Ethiopia. Pp. 49-53.

Mulugete, T., Batu, G., \& Bitew, M. (2011). Prevalence of gastrointestinal parasites of sheep and goats in and around Bedelle, South-Western Ethiopia. Int. J. Vet. Med. 8(2), 1425.

NIMET (2011). Nigeria Metrological Agencies, Synoptic Office, Lafia, Nasarawa State, Nigeria.

NPC (2006). National population and housing census, National Population Commission, Abuja Federal republic of Nigeria.

Okaiyeto, S. O., Tekdek, L. B., Sackey, A. K. B., \& Ajanusi O. J. (2008). Prevalence of haemo- and gastro-intestinal parasites in sheep and goats kept by the Nomadic Fulani in some Northern States of Nigeria. Res. J. Anim. Sci., 2(2), 31-33.
RIM (1992). Nigerian Livestock resources. Four volumes report to the Federal Government of Nigeria. Submitted by Resource Inventory Management Limited. 1. Executive Summary and Atlas. 2. National synthesis. 3. State Reports. 4. Urban Reports and commercially managed livestock survey report.

Shahadat, M. A., Karim, M. J., Alam, M. Z., \& Majumder, S. (2003). Seasonal distribution of Haemonchus contortus in Bengal goats. The Bangl. Veterinarian. 20, 72-76.

Williamson, G., \& Payne, W. J. A. (1978). An introduction to animal husbandry in the tropics ( $3^{\text {rd }}$ Edn.), Longman Group Limited, UK. p. 755.

Yeasmin, T., Khanum, H., \& Zaman, R. F. (2014). Seasonal prevalence of Arthropoda and helminth parasites in sheep (Ovis aries). Bangl. J. Zool., 42(1), 45-55. 